\title{
Correction to: Comparative Assessment of the New PDE7 Inhibitor - GRMS-55 and Lisofylline in Animal Models of Immune-Related Disorders: A PK/PD Modeling Approach
}

Artur Świerczek' - Krzysztof Pociecha' • Marietta Ślusarczyk ${ }^{2}$ - Grażyna Chłoń-Rzepa ${ }^{2}$.

Sebastian Baś $^{3} \cdot$ Jacek Mlynarski ${ }^{3,4} \cdot \mathrm{Krzysztof} \mathrm{Więckowski}^{5}$. Monika Zadrożna ${ }^{6}$.

Barbara Nowak ${ }^{6}$ • Elżbieta Wyska' (D)

Published online: 21 January 2020

(C) Springer Science+Business Media, LLC, part of Springer Nature 2020

\section{Correction to: Pharm Res \\ https://doi.org/10.1007/sI 1095-019-2727-z}

There was a mistake in the unit of clearance $(C l)$ in Table II. In addition, the descriptions of $V_{1(R O L)}$ and $V_{1(G R M S-55)}$ were imprecise and the reference number in the footnote below this table should be (9). The corrected Table appears below.

The online version of the original article can be found at https://doi.org/l 0 . |007/s | |095-0 | 9-2727-z

\footnotetext{
Elżbieta Wyska

mfwyska@cyf-kr.edu.pl

Department of Pharmacokinetics and Physical Pharmacy, Jagiellonian University Medical College, 9 Medyczna Street, 30-688 Kraków, Poland

2 Department of Medicinal Chemistry, Jagiellonian University Medical College, 9 Medyczna Street, 30-688 Kraków, Poland

3 Faculty of Chemistry, Jagiellonian University, Gronostajowa 2. 30-387 Kraków, Poland

4 Present address: Institute of Organic Chemistry, Polish Academy of Sciences, Kasprzaka 44/52, 01-224 Warsaw, Poland

5 Department of Organic Chemistry, Jagiellonian University Medical College, 9 Medyczna Street, 30-688 Kraków, Poland

6 Department of Cytobiology, Jagiellonian University Medical College, 9 Medyczna Street, 30-688 Kraków, Poland
} 


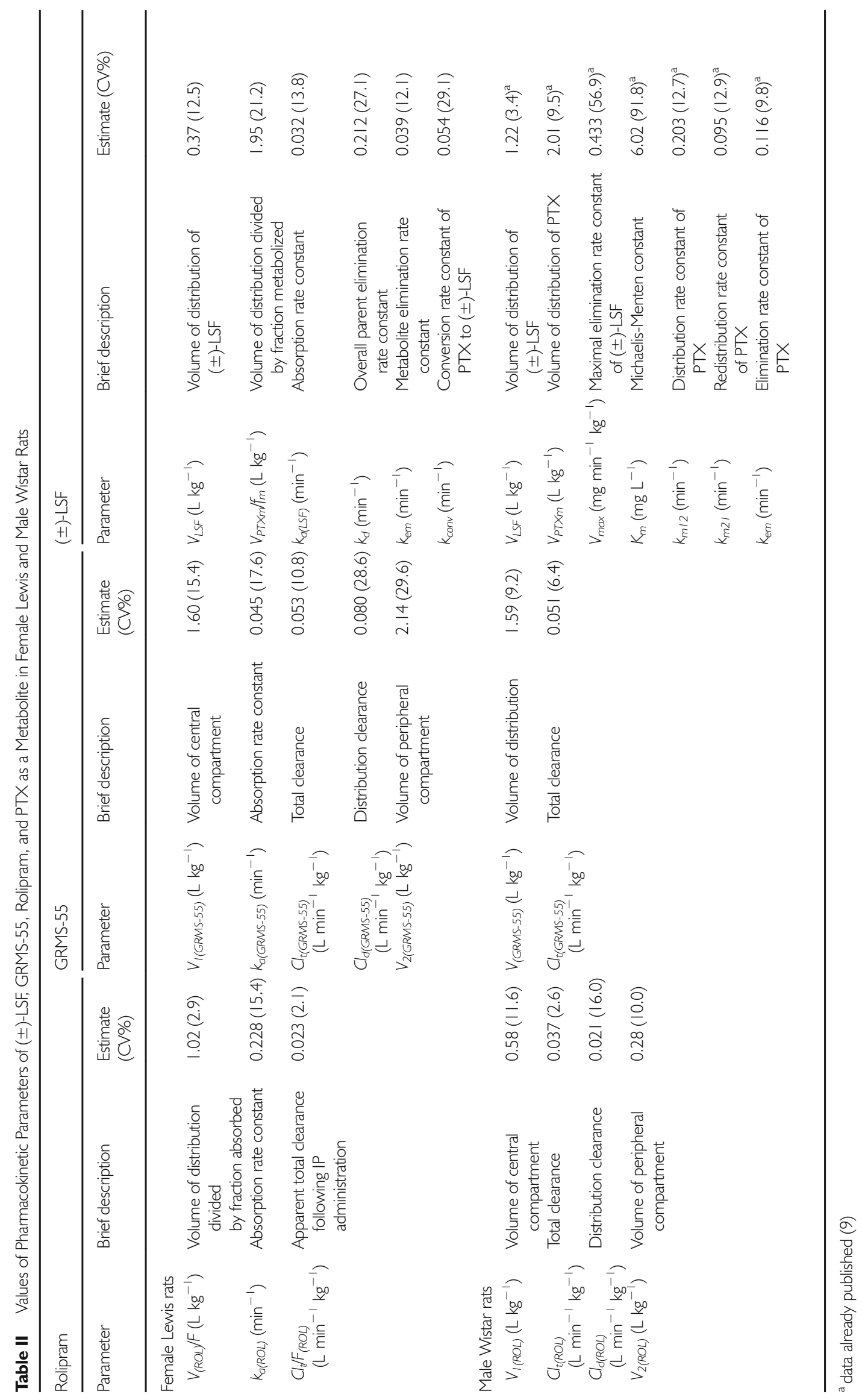

